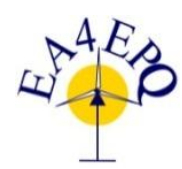

International Conference on Renewable Energies and Power Quality (ICREPQ'13)

Bilbao (Spain), 20 $0^{\text {th }}$ to $22^{\text {th }}$ March, 2013

Renewable Energy and Pourer Quality. Fournal (RE\&PQJ)

ISSN 2172-038 X, No.11, March 2013

\title{
Evaluation of Renewable Energy Technologies in a net Zero Energy Office Building in Germany
}

\author{
L. Spitalny ${ }^{1}$, D. Unger ${ }^{1}$, J. Maasmann ${ }^{1}$, P. Schwerdt ${ }^{2}$, B. Van Reeth ${ }^{3}$, A. Thiemann ${ }^{4}$, and J.M.A. Myrzik ${ }^{1}$ \\ ${ }^{1}$ Institute of Energy Systems, Energy Efficiency and \\ Energy Economics, TU Dortmund University, Emil-Figge-Str. 68, \\ 44227 Dortmund (Germany) \\ Phone number: + 49231755 4305, e-mail: lukas.spitalny@tu-dortmund.de \\ ${ }^{2}$ Fraunhofer Umsicht, Energy Efficiency Technologies, \\ Osterfelder Straße 3, \\ 46047 Oberhausen (Germany) \\ Phone number: +49 2088598 1173, peter.schwerdt@umsicht.fraunhofer.de \\ ${ }^{3}$ Daikin Europe NV, Environment Research Center, Chaussee de Mons 1424 \\ 1070 Brussels, (Belgium) \\ Phone number: +32 25296111 , vanreeth.b@bxl.daikineurope.com \\ ${ }^{4}$ TecneXum GmbH, ZEFFLE - durable sun reflective coating \\ Walpurgisstr, 42 \\ D-45131 Essen (Germany) \\ Phone number: +49 201958 7043, a.thiemann@tecnexum.com
}

\begin{abstract}
Besides increasing requirements for the thermal insulation of buildings, renewable energy sources as photovoltaic-systems as well as heat pumps become more important in the building sector. Until now, there is no sufficient experience of the operation of these units in net zero-energy buildings. Due to this, Daikin Europe NV and Athoka GmbH initiated a test lab to analyse the operation in a daily office routine. To coordinate the power supply and demand of the building, an energy management system is used. To achieve an efficient heating and cooling the operation of two air-to-water and one air-to-air heat pumps was combined. Furthermore, the impact of high reflecting roof coating on the photovoltaic yield was analysed. For this reason, the effectiveness of the energy management system and the combined operation of the heat pumps are evaluated in this paper. In addition, the paper points out the central points for achieving the net zero-energy goal.
\end{abstract}

\section{Key words}

Net Zero-Energy Building, Heat Pumps, Renewable Energies, Energy Management System

\section{Introduction}

The energy consumption of buildings amounts for $40 \%$ of the total energy consumption in the European Union and thus shows a large potential for efficiency measures. According to this, the energy performance of buildings directive (EPBD) demands that all new buildings shall be nearly zero-energy buildings by 31 December 2020. [1] To fulfil the sophisticated requirements of the EPBD certain measures as improving the thermal insulation of buildings and also the use of renewable energy resources are inevitable.

To evaluate these measures in a daily office routine, Daikin Europe NV and Athoka GmbH initiated a test lab in a new office building in Herten which is in the Ruhr area in Germany. Heat pumps (HP) are used for covering the thermal heat demand of the building. The investors went a step further and set the more ambitious target that the office building shall be a net zero-energy building (nZEB). This can be defined as a building, which produces as much energy as it uses during a year. [2] For this reason a photovoltaic (PV) system was installed on the building.

The nZEB-goal can only be achieved by an optimized energy management system (EMS) with the aim of an efficient energy use. For this reason, the effectiveness of the EMS is analysed and verified. Furthermore, the PVsystem is analysed and it is evaluated, how the PV-yield can be increased by the use of high reflecting roof coatings. The efficiency of the combined operation of the various HP-systems is analysed and improvements for the operation are identified.

\section{Description of the realized net Zero- Energy Building Test Office}

The nZEB test office consists of several technologies among others for heating, cooling, lighting and using renewable energy sources. The building is separated in two parts, the warehouse and the office building, which can be seen from Fig. 1. The further considerations 
concentrate on the office building. This has two floors and a specific primary energy consumption of $37.7 \mathrm{kWh} / \mathrm{m}^{2} \mathrm{a}$, which is covered by a HP based heating system. The thermal base load is covered by two air-to-water HPs for floor heating, called Daikin Altherma. The ground floor is supplied by the Daikin Altherma L0 and the $1^{\text {st }}$ floor is supplied by the Daikin Altherma L1. The remaining heat demand, especially in times of high fluctuation is covered by an air-to-air HP, which is called VRV. The aim of this combination is to reach a high efficiency of the heat provision. To reach the nZEB-goal a PV-system, with a peak power rating of $27.3 \mathrm{kWp}$ is installed on the roof.

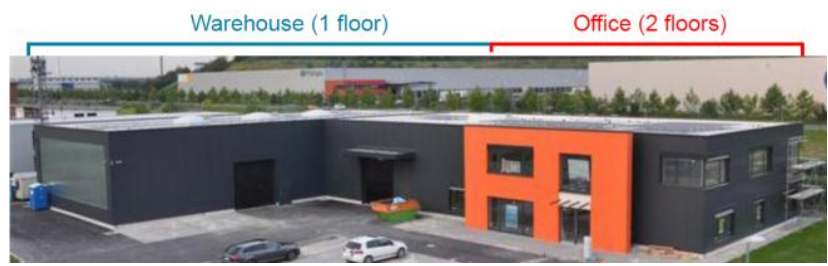

Fig. 1. net Zero-Energy Building Test Office in Herten [2]

An EMS is implemented on a high level in order to coordinate the operation of heating, cooling and lighting systems in the building. For this reason, more than 500 sensors are installed in total. To monitor and evaluate the user-related climate comfort in detail, one office on the ground floor and one on the upper floor were chosen and especially equipped with a variety of sensors (temperature of air, floor, heating water, outside wall, rel humidity, $\mathrm{CO}_{2}$ concentration, light intensity, occupancy, window and shutter status and others), as shown in Fig. 2. The air temperature was measured at different heights, at the bottom, in the middle and the top of the room.

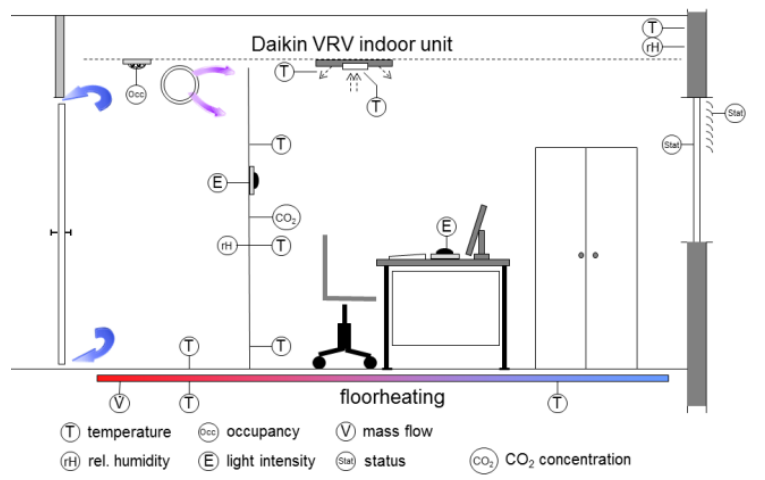

Fig. 2. Sensor equipment of the two test offices

\section{Effectiveness of the Building Energy Management System}

The effectiveness of the EMS is estimated in a first test and measuring period which took place from March 2011 to February 2012. Throughout the measuring period, the weather conditions were moderate with very sunny months from April to June but cloudy months in summer and a relative warm winter.

For the nZEB-consideration, only the energy demand is included that is necessary for heating, cooling, ventilation, lighting, and for domestic hot water. Any further energy demand, as appliances in the office is not included. [3]
The monthly nZEB-energy demand and the PV-generation for the measuring period are visualized in the following figure.

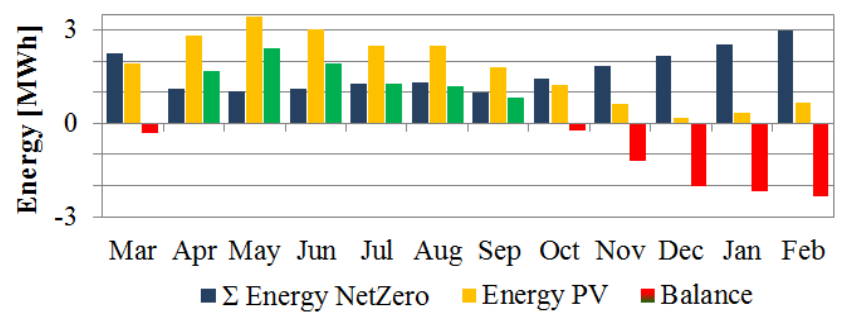

Fig. 3. Monthly energy consumption and generation of nZEBHerten

The energy balance is positive in the months of April to September. In these months, the energy generation by the PV-system is much higher than the demand. In the months of October to March, the balance is negative because of the lower radiation. During the measuring period the sum of the energy demand amounts to $19,975 \mathrm{kWh}$. Compared with the yield of the PV-system, which is $20,970 \mathrm{kWh}$, the nZEB-energy demand can be covered up completely. Hence, the nZEB-goal was reached in the first measuring period, which initially verifies the effectiveness of the EMS. However, this applies at first only for the first measuring period. A lot of influences can impinge upon the nZEB-goal over the year, as

- change in consumption,

- bad weather conditions (temperature as well as solar radiation),

- and drop in the efficiency of the PV-system.

According to this, it is possible that the nZEB-goal may not be reached in the future if the conditions deteriorate. Hence, the energy consumption and generation needs to be reviewed regularly and adapted, if necessary.

\section{Analysis of the Installed Photovoltaic System}

The nZEB is defined as a building that produces as much energy as it uses during a year. For this reason, a PVsystem was installed on the building. The special PVsystem of the nZEB test office was used to analyse the impact of high reflecting coating on the PV-yield, which is described in the following. For the PV-system special lightweight cylindrical PV-panels of copper-indiumgallium-diselenide (CIGS) from Solyndra ${ }^{\circledR}$ are used. The PV-system is mounted on the roof, which is coated with a layer of white polymer. Each panel consists of 40 tubes that are 1 meter long. The thin-film solar cells are arranged all around in the tube so that the solar radiation can be used for $360^{\circ}$ around the tubes. The power rating of one panel is $182 \mathrm{Wp}$. The power rating is measured at standard test conditions at laboratory conditions with a radiation of $1,000 \mathrm{~W} / \mathrm{m}^{2}$ and a cell temperature of $25^{\circ} \mathrm{C}$. With a number of 150 panels, the installed power rating results in $27.3 \mathrm{kWp}$. [4]

The installed PV-system was used for analysing the impact of a high reflecting coating (HR-coating) for so 
called cool roof technologies. HR-coatings can be attached on a roof with the primary objective to reduce the cooling demand of the building by reflecting of more than $90 \%$ of the solar irradiation. For this reason, the effect of the higher reflectance on the PV-yield was analysed by attaching a separate area on the roof with a market available HR-coating called ZEFFLE ${ }^{\mathrm{TM}}$ [2].

Hence, two measurement fields were arranged on the roof with 15 PV-panels per field. The roof below one of these fields was covered with the HR-coating and thus called the ZEFFLE-field. The roof of the reference field is coated with a layer of white polymer. Fig. 4 shows the effect of the higher reflectivity on the PV-system that leads to a higher irradiation on the cylindrical PV-cells, exemplarily.

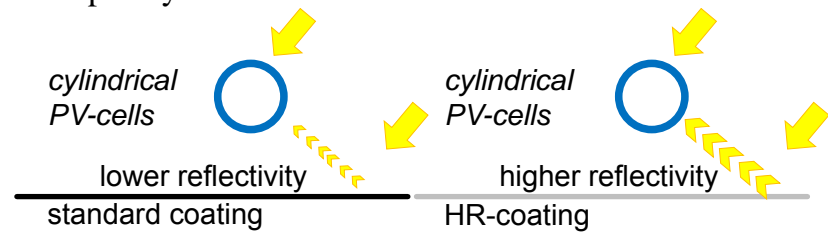

Fig. 4. Effect of HR-coating on the PV-system

Every field was equipped with sensors in order to measure the temperature of the roof and of the PV-panels, as well as to measure the current and the voltage. Since, the ZEFFLE-field was installed in the third month of the measuring period, only data from June up to February are available. Nevertheless, the measured data show that the yield of the ZEFFLE-field is higher than the yield of the reference field. Fig. 5 shows the measured energy from both, the ZEFFLE and the reference field. Furthermore, the difference of the power generation $\Delta P$ between the ZEFFLE-field $P_{\text {ZEFFLE }}$ and the reference field $P_{\text {reference }}$ is shown, which can be described by following equation:

$$
\Delta P=\frac{P_{Z E F F L E}}{P_{\text {Reference }}}
$$

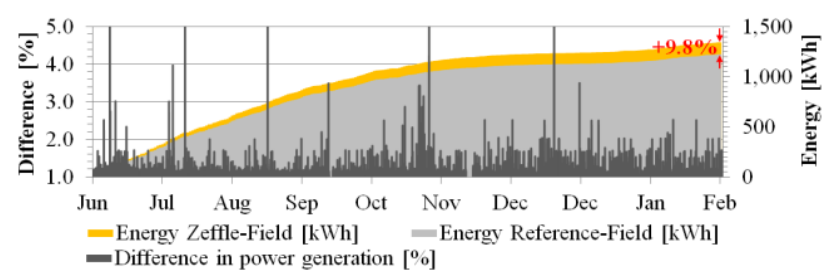

Fig. 5. Comparison of the power from reference field and the ZEFFLE field

Already after 9 months the PV-yield of the ZEFFLE-field is $9.8 \%$ higher than the yield of the reference-field. Consequently, the use of a HR-coating can increase the benefit of a PV-system. The influence on the PV performance is not the only task of a HR-coating in fact. Another aim of the coating is to reduce the cooling demand of a building. If the HR-coating is attached on a building for this reason, there can be a benefit in combination with a PV-system. In the case that the HRcoating is attached only to increase the PV-yield, case by case should be assessed if the surplus of energy covers the additional expenditure for the HR-coating. Thus, the economic efficiency for this case needs to be investigated in detail.

\section{Efficient Heating and Cooling with VRV / Daikin Altherma}

In the nZEB test office the investors had combined and fully integrated some core HVAC products to ensure maximum energy efficiency and a high level of personal comfort for the customer and the users of the building. Fraunhofer UMSICHT was commissioned to monitor and evaluate these HVAC systems, consisting of a combination of two air-to-water Daikin Altherma HP for floor heating, a VRV air-to-air system and a VAM ventilation system.

The main topic was to evaluate the load sharing of the heat pumps, the primary energy demands, the coefficientof-performance (COP) and the room climate comfort over a one year period. Furthermore, the heating/cooling and indoor climate parameters of two selected office rooms were especially investigated.

\section{A. Monitoring of VRV-Daikin Altherma Combination}

Both heat pump systems use ambient air as the heat source. Each system was designed to cover the full heat load but was meant to fulfil various tasks. The thermally inert water based floor heating of both ground floor and $1^{\text {st }}$ floor, is supplied from the Daikin Altherma HP in order to supply the base thermal load of the building. The fast reacting air-to-air VRV system with its distributed indoor units was meant to deliver the fluctuating flexible load whenever required. Additionally, the reversible VRV was used for cooling and air conditioning in summer. Fig. 6 shows the possible task sharing of various heat pump systems, whereby the respective task settings can be freely adjusted.

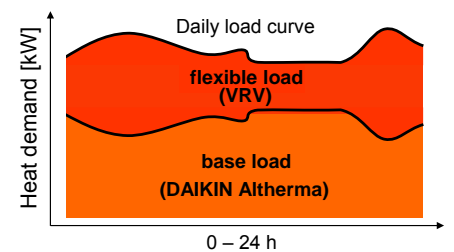

Fig. 6. Possible task sharing of two heat pump systems to meet fluctuating heat demand

To evaluate the possible benefits of task sharing these two systems were used in several combined and stand alone modes, to gain information on their performance behaviour and the building indoor climate.

The measurement results show that the installed systems were almost exactly matching the predicted performance and ensuring a comfortable indoor climate throughout the whole year. However, the cooling capacity of the VRV system was over-dimensioned considering the actual low cooling demand, which was observed during the monitoring period. This is presumably due to the particular character of the building with its rather large floor area and offices, which were not always occupied. The indoor units of the test offices also seem to be rather powerful, thus being able to reach the set point temperatures very quickly. The building characteristics are briefly represented in the annual load duration curve in Fig. 7 below. The shape of the load curve indicates that the maximum thermal load of about $33 \mathrm{~kW}$ was just 
demanded a few hours within the 12 months period, which was actually in the short freezing period of January and February 2012. It can also be read from the diagram that the VRV was operating for heating just about 550 hours in total, while both air-to-water HP were working about 3,700 hours. Thereby, at least one unit was operating or both units operated parallel, which is rather due to the showcase character of the building.

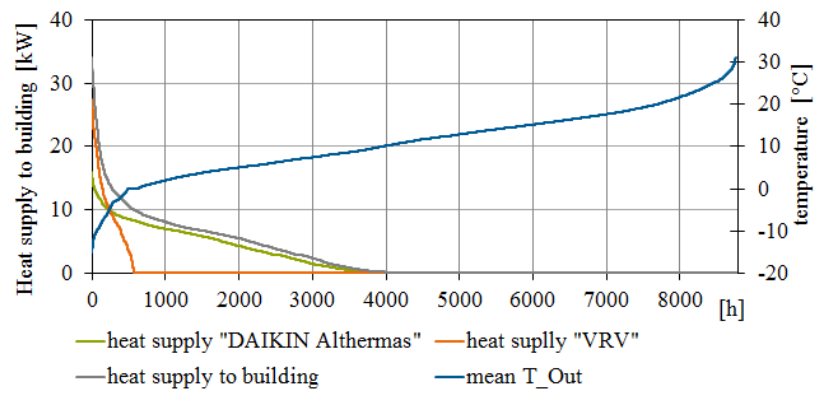

Fig. 7. Annual load duration curve (sorted)

The initially feared possibility of heating and cooling at the same day, which would be energetically disadvantageous, was not occurring. In order to evaluate the effects of various task settings the operation of the heat pumps was adapted in the cold winter period of January 2012. At first, the VRV system was set off so that just the Daikin Altherma HPs were operating in a constant "day mode". As can be seen from Fig. 8, the indoor temperature, as mean values of all offices, showroom and reception, remained quite constant.

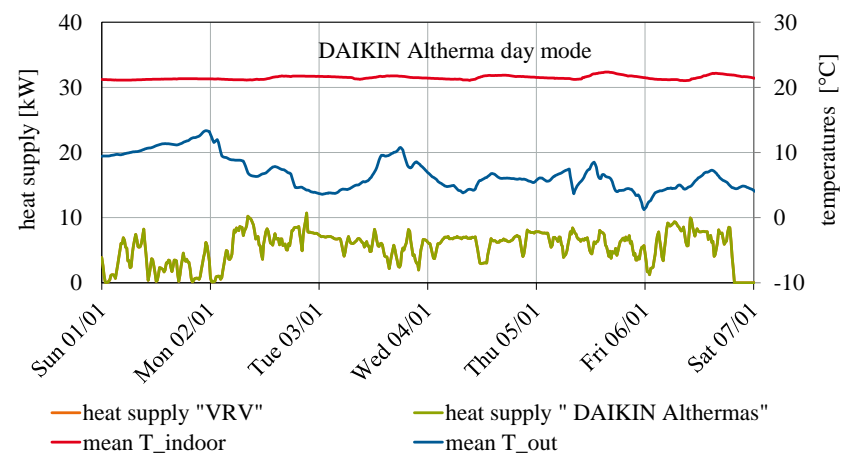

Fig. 8. Mean indoor temperatures at Daikin Altherma only mode

In contrast, significant variations of the mean indoor temperature can be seen, if the thermal heat demand is mainly supplied by the VRV system as mentioned in Fig. 9. The temperature fluctuation is significantly increased in comparison to the Daikin Altherma day mode. It can be stated that at least in winter time the floor heating was advantageous in providing a comfortable feeling due to more equal air, floor and wall temperatures, compared to the ceiling mounted VRV indoor units. The advantage of the VRV system is the very fast reaching of the room set temperature and thus a high efficiency for office buildings in particular. During office time, the VRV system can heat up real quickly whereas it can be switched off during night times and thus avoid consumption. Hence, the combination of the thermally inert water based floor heating and the very fast VRV system is very efficient and favourable for a comfortable indoor climate.

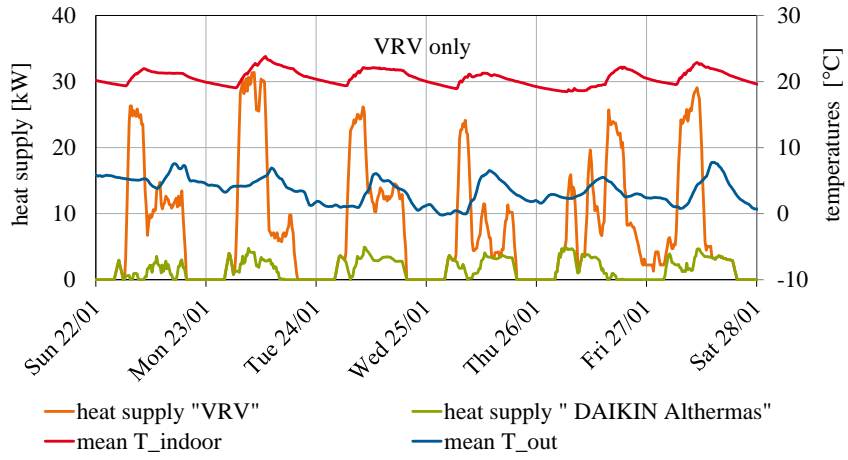

Fig. 9. Mean indoor temperatures at "VRV only" mode

Nevertheless, some parameters and functions of the building systems were still subject to optimization during this first year of operation and thus some deviations from the desired set points were occurring.

The performance of the HP is estimated by the seasonal COP which is based on the measured heat output $Q_{t h}$ and the consumed electric energy $W_{e l}$ (including pumps, valve drives and controls) for the considered period, as can be seen from Eq. (2).

$$
\text { Seasonal COP }=\frac{Q_{t h}}{W_{e l}}
$$

Fig. 10 shows the measured heat supply of both air-towater HP for every month. Also, the calculated seasonal COP and the ambient air temperature can be seen. The overall COP is around 3.5 to 4 under sufficient heating load conditions like in the winter time. The slightly reduced COP values at the end of the measuring period in January and February are due to low ambient temperatures and humid weather conditions with the need of frequent defrosting of the evaporator. Additionally, the test program of the HP-system (according to Fig. 8 and Fig.9) with its sometimes exceptional operating conditions impinge on the seasonal COP. It must be pointed out that fine-tuning and optimization of all HVAC systems will first be done after the monitoring period. Thus, the resulting COPs are lower than in an optimized HVAC system.

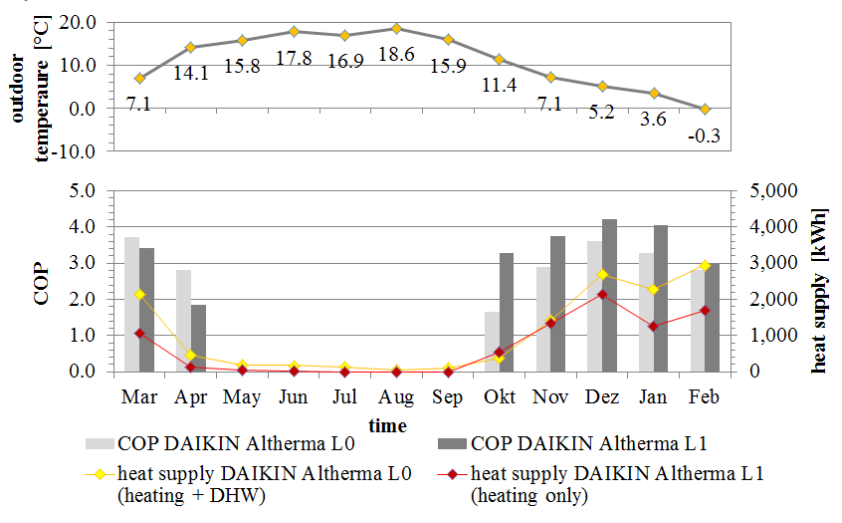

Fig. 10. Daikin Altherma HP L0 and L1 - monthly heat output and average COP

Due to the mild outdoor temperatures between April and September, the building energy demand for space heating was quite low. Thus, the air-to-water HP were operating just at very low partial load or even remain in standby 
mode. Since, the Daikin Altherma L0 is also supplying the domestic hot water (DHW) system throughout the year, it has a heat supply between April and September, which was very low. As the seasonal COP is strongly dependant on the load level, therefore no meaningful monthly COP could be calculated outside the heating season (May to Sep).

According to this, in office buildings or buildings with a similar consumption profile with a very low DHW demand, the few tapping points should rather be supplied by decentralised systems with low heat losses and low standby consumption. Due to the low daily hot water demand this would be in line with the design options of water heaters according to the European Ecodesign Directive [8].

Due to the fact that the VRV system with its distributed indoor units does not allow to measure the heat output directly and in a simple way, the seasonal COP was not calculated for this consideration.

\section{B. Improvement potential of the control concept}

During testing of various system configurations and load sharing of the VRV and the DAKIN Altherma heat pump, no significant difference in the energy efficiency could be observed. Following the observations from the configuration tests it is rather recommended to run the heating systems rather more constant in periods of high building heat demand, to avoid load peaks with lower evaporator and increased condenser temperatures. Secondly, it is favourable to ensure a continuous operation with no or a rather moderate night set back thus preventing the building from cooling off at night as well as avoiding large room temperature spreads during office hours and low temperatures in problematic locations, e.g. under a desk near the outwall. Therefore, for future nZEB projects the selection of the heat pump system should also consider monetary and architectural aspects as well as the expected cooling load in summer.

Additionally, it became apparent from the energy meters of the HVAC systems that several hundred kWh p.a. of standby consumption could be saved by a complete shutoff when being out of use for a longer time. An integrated management building control could determine the periods where a complete shut-off would be advantageous.

As the evaluation of the test offices has shown, the fresh air supply of the VAM ventilation just plays a minor role in the overall heat balance, which is due to the low heat capacity of air and the low temperature difference to the room conditions. Nevertheless, in times of high heating or cooling load, the VAM performance could be reduced to relieve the supply systems or save energy. This could be done by increasing the bypass flow, reducing the fan speed or even temporarily turning the system off.

\section{Combination of renewable energies with high reflecting coating}

As mentioned before, the HR-coating can increase the benefit of a PV-system. To analyse the influence of HRcoatings and to determine advantages in combination with renewable energy technologies, TU Dortmund University performed various measurements.

The optical performance of the roof coating on a factory building was analysed in August 2012 in Gelsenkirchen, Germany. The static construction of the roof is based on trapezoidal sheets with a thermal insulation of $60 \mathrm{~mm}$ thickness. On August $13^{\text {th }}$ the thermal performance of the existing black bitumen coating was measured. Afterwards, a HR-coating was attached on the roof and the thermal performance was measured on August $16^{\text {th }}$. Fig. 11 shows the measurement results. It can be seen that the reflecting power of the surface (albedo) of the HR-coating is higher than the albedo of the black bitumen. The measured average albedo of the HR-coating is 0.81 whereby the average albedo of the black bitumen is 0.09 . It can be seen that the black bitumen coating heated up to $70^{\circ} \mathrm{C}$, whereas the absolute temperature of the HR-coating remains below $30^{\circ} \mathrm{C}$. In addition, the indoor temperatures of a test room were measured, which has a size of $4.5 \mathrm{~m} \times 15.15 \mathrm{~m}$ and a height of $5.4 \mathrm{~m}$. The test room is cooled by an air conditioning system. Two temperature measurement points were installed at a height of $1.2 \mathrm{~m}$ and at $5.4 \mathrm{~m}$, respectively. With the black bitumen coating the mean value of the temperature difference is $6.6^{\circ} \mathrm{C}$. After attaching the HR-coating the mean value of the temperature difference decreases to $3.7^{\circ} \mathrm{C}$.

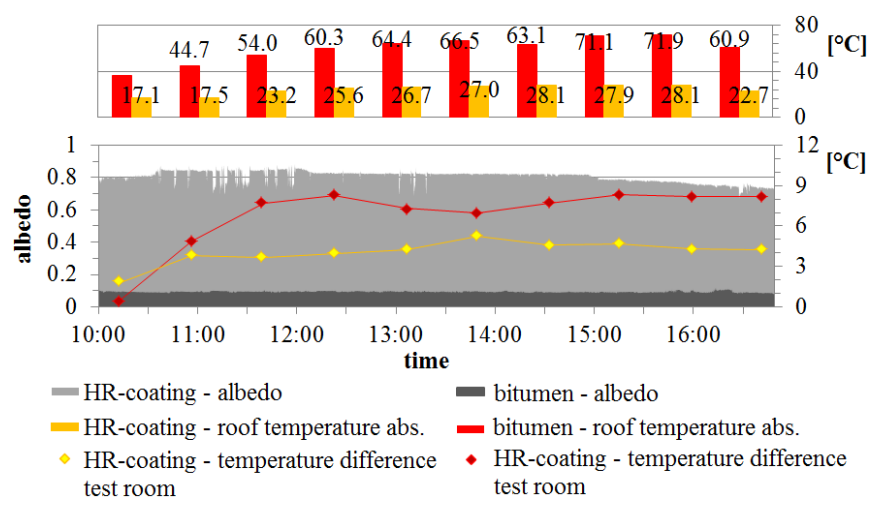

Fig. 11. Measurements of thermal performance of high reflecting coating and bitumen on a factory building in Gelsenkirchen

Another measurement was performed in a bungalow in Sluis, Netherlands. The roof is a wooden beam construction without insulation and a black bitumen coating. The measuring procedure was split in several parts. On $26^{\text {th }}$ July 2012 the optical performance of the black bitumen coating was measured whereas the afterwards attached HR-coating was measured on $18^{\text {th }}$ August. The results of the measurements can be seen in Fig. 12. In contrast to the measurements in Gelsenkirchen, the measurements were not carried out continuously, but were carried out at discrete time steps. The measured albedo of the black bitumen coating is between 0.13 and 0.16 , whereby the measured albedo of the coated surface is between 0.75 and 0.90 . Furthermore, the temperature of the roof and the air temperature at a height of $0.5 \mathrm{~m}$ above the roof coating were measured and compared to the ambient temperature. It can be seen that for the bitumen coating the difference between roof and ambient temperature is higher. Also, the gap between the difference of the roof temperature and the roof 
temperature at $+0.5 \mathrm{~m}$ is higher for the bitumen coating. The HR-coating shows only a minimal gap, whereby the bitumen coating shows a higher gap. It should be noticed that inaccuracies occur for the temperature measurement. Since, the temperature sensor on the roof has another emissivity and reflectivity than the roof coating, it heated up differently by the solar irradiation. Thus it can be assumed that the gap between bitumen coating and air temperature is higher. Whereas it can be assumed that the gap between HR-coating and air temperature is lower (according to images from an infrared camera [6]).

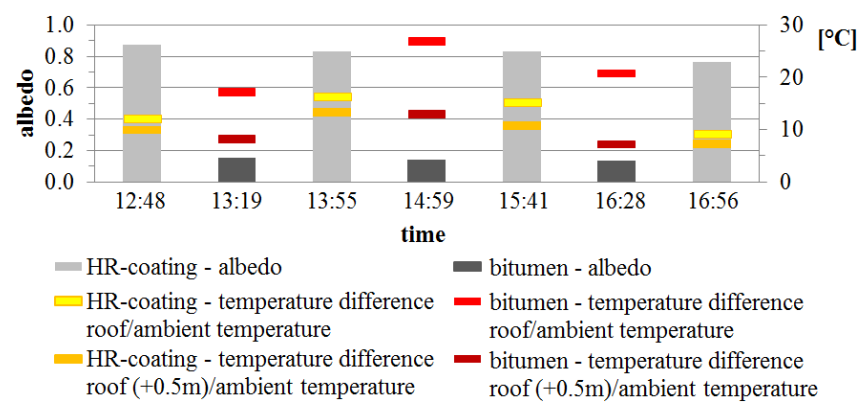

Fig. 12. Measurements of thermal performance of high reflecting coating and bitumen on a bungalow building in Sluis

It can be summarized that HR-coatings show following effects compared to black bitumen coatings:

" higher reflecting power of the surface (albedo)

- lower temperature of the roof surface

- lower air temperature in low altitude over the roof

- lower indoor air temperature in rooms directly connected to the roof

Accordingly, it can be concluded that the application of a HR-coating can increase the benefit of renewable energy technologies and can increase the efficiency of building air conditioning. The higher albedo of the HR-coating can increase the yield of PV and solar thermal systems [7]. The lower temperature of the roof surface has a positive influence on HVAC systems, if the outdoor unit is placed on the roof. Since, the air temperature above the HRcoating is lower, the inlet air temperature decreases and the efficiency for cooling increases. Additionally, lower temperatures under the roof causes a decreasing cooling demand. Therefore, HR-coatings can contribute to reach sophisticated nZEB-goals.

\section{Conclusions}

The monitored period has proven that the use of renewable energy technologies and the EMS is suitable for reaching the sophisticated nZEB-goals. The calculated values for the building demand were reached and the design of the building system was proven. Whereas, the measurements need to be carried out to get more detailed data and thus a long-term evaluation.

The energy balance of the building shows that the PVyield covers up the energy demand for the nZEBconsideration in the first year. It can be seen that attaching a high reflecting coating on the roof has a positive influence on the PV-yield. If the high reflecting coating is attached to reduce the roof temperature and thus the cooling demand of a building, the yield of a mounted PVsystem will increase. Whereby it should be noted that the cost efficiency of a HR-coating for increasing the PVyield needs to be investigated in detail.

Because a lot of influences can lead to a change in the yearly energy production of the PV-system and the energy demand, the nZEB-consideration must not be limited to one year, but needs to be considered over a longer period. The monitored period has shown that the HP-system is ensuring the desired climate conditions whenever the rooms were used for normal office work. Nevertheless, the prior aim of the designed combination of the HPsystem was to evaluate several operation modes and tasks in a nZEB. In order to reach high cost efficiency and to fulfil architectural aspects, the design of the HP-system needs to be optimized for future nZEB. According to the specific thermal consumption profile of office buildings, the operation of a HVAC system can be optimized by an integrated EMS with for example the possibility of a night set back operation. It is doubtful whether the supply of DHW by HP is efficient for a nZEB office building. Especially, in periods of low thermal demand for space heating the COP of the HP decreases if it just supplies the DHW system. Thus, decentralised heating system seems more favourable for comparable office buildings.

\section{References}

[1] DIRECTIVE 2010/31/EU OF THE EUROPEAN PARLIAMENT AND OF THE COUNCIL of 19 May 2010 on the energy performance of buildings (recast).

[2] B. V. Reeth, "Daikin nZEB project: HERTEN", Daikin Europe NV, REHVA - AICARR Seminar on Zero Energy Buildings, Milan, March 2012.

[3] DIN V 18599-1 "Energy efficiency of buildings Calculation of the net, final and primary energy demand for heating, cooling, ventilation, domestic hot water and lighting -Part 1: General balancing procedures, terms and definitions, zoning and evaluation of energy sources", December 2011

[4] Solyndra, Data Sheet Solyndra 100 Series, Revision 8, Fremont, CA, USA, 12.08.2010. [Online]. http://www.solyndra.com

[5] J. Maasmann, "Report on the measuring process of the optical and thermal performance of a cool roof in factory building - Gelsenkirchen (Germany)", project report, TU Dortmund University - $\mathrm{ie}^{3}$, Dortmund, November 2011.

[6] J. Maasmann, "Report on the measuring process of the optical and thermal performance of a cool roof in bungalow - sluis (Netherlands)", project report, TU Dortmund University - $\mathrm{ie}^{3}$, Dortmund, November 2011.

[7] J. Maasmann, J.M.A. Myrzik, A. Thiemann, B. Van Reeth, "Effizienzsteigerung von Photovoltaik-Modulen durch hochreflektierende Untergrundbeschichtungen auf Flachdächern" accepted for 5. Anwenderforum Bauwerkintegrierte Photovoltaik, März 2013, Kloster Banz, Bad Staffelstein, in press.

[8] R. Kemna, M. van Elburg, W. Li, R. van Holsteijn, "Preparatory Study on Eco-design of Water Heaters - Task 6 Design Options (Final)", Van Holsteijn en Kemna BV (VHK), Delft, September 2007. 